\title{
El poder del prosumidor. Identificación de sus necesidades y repercusión en la producción audiovisual transmedia
}

The power of prosumer. Identification of their needs and impact in transmedia audiovisual production

\author{
Ana Lastra
}

Consultora de gestión cultural y producción audiovisual

Fecha de recepción: 28 de septiembre de 2015

Fecha de revisión: 13 de diciembre de 2015

Para citar este artículo: Lastra, A. (2016): El poder del prosumidor. Identificación de sus necesidades y repercusión en la producción audiovisual transmedia, Icono 14, volumen (14), pp. 71-94. doi: 10.7195/ri14.v14i1.902 


\section{Resumen}

Un producto audiovisual transmedia se fundamenta en tres pilares: un universo narrativo, un número de plataformas de expansión de ese universo y un prosumidor que interactúe con el contenido. El presente trabajo supone un análisis de este prosumidor. Para ello, se ha realizado una documentación bibliográfica y un desarrollo comparativo de dos estudios de caso: El Ministerio del Tiempo y Kung Fury. Se optan por estos dos proyectos debido a sus diferencias tanto en su sistema de producción como en su prosumidor objetivo. Este análisis se realiza para observar cuáles son las necesidades del prosumidor y su repercusión en la viabilidad del proyecto. Se intenta, además de identificar el poder del prosumidor en la producción audiovisual transmedia, establecer qué aspectos relacionados con la comunicación deben reforzarse y/o mejorar de cara al futuro. Todo ello para obtener un feedback constructivo entre los medios de comunicación y el prosumidor.

Palabras clave: Narrativa transmedia - Prosumidor - Alfabetización mediática Contenido generardo por el usuario - Producción audiovisual

\section{Abstract}

Transmedia audiovisual products have three basic pillars: a narrative universe, a number of expansion platforms of these universe and a prosumer who interacts with the content. This work represents an analysis of this prosumer. A bibliographic documentation and comparative work have been used for this two case studies, El Ministerio del Tiempo and Kung Fury. These two projects have been chosen because of their differences on production system and objective prosumer. All this analysis was made to determine which are the prosumer's necessities and repercussion in the viability of the project. As well as identifying the power of prosumer in transmedia audiovisual production, it tries analyzing what communications aspects must be strengthen and/or improve in the future. All this work gives us a constructive feedback between mass media and prosumer.

Key Words: Transmedia storytelling - Prosumer - Audiovisual production - User-generated content - Digital alphabetization 


\section{Introducción}

La aparición de la web 2.0 y la digitalización del contenido producido por las industrias culturales han modificado los hábitos de consumo de la audiencia.

El "cuándo", "dónde" y "cómo" se reproduce un contenido se ha convertido en una elección personal del espectador. Los accesos a productos audiovisuales a través de, por ejemplo, las páginas web de cadenas de televisión o videoclubs online permite elegir la hora y el día más idóneo para su visionado. Además, el acceso multidispositivo (ordenador, aparato televisivo, tablet, móvil) constituye una modificación del lugar e, incluso, puede individualizar su consumo dentro del ámbito familiar.

Por otro lado, este mismo espectador ha modificado su comportamiento respecto al contenido que consume, llegando a convertirse en una persona multitarea. La atención en la obra audiovisual se ve diversificada: consumo del contenido, búsqueda de información sobre éste, opiniones, comentarios y valoraciones para otros espectadores a través de las redes sociales y hasta producción de su propio contenido relacionado.

Este proceso de transformación del espectador desencadena que el propio término quede obsoleto ante su nuevo comportamiento. Surge así, el prosumidor, un concepto que, aunque nuevo dentro de la esfera audiovisual, lleva siendo tema de debate desde su aparición. En la década de los 80, Alvin Toffler, lo acuñó para referirse a una tercera etapa económica en la sociedad durante la cual las personas producen parte de su propio consumo.

Estas modificaciones en el consumo audiovisual, Internet y la convergencia de medios han sido el caldo de cultivo de la aparición de nuevas narrativas: narrativa crossmedia (televisión, web, radio y otros confluyen para contar una misma historia), crossover (combinación de varias historias en un mismo relato) y transmedia.

La Narrativa Transmedia fue definida por Henry Jenkins en el año 2003 como "un proceso donde elementos integrantes de una ficción aparecen dispersos a través 


\section{MONOGRÁFICO}

de múltiples canales de distribución con el propósito de crear una experiencia de entretenimiento unificada y coordinada".

Desde esa fecha, los proyectos de carácter transmedia han ido creciendo en número y en calidad tanto a nivel nacional como internacional. Incluso la aplicación de la estructura transmedia se ha llevado a cabo en marketing, educación y periodismo.

En cuanto a obras audiovisuales transmedia existen una infinidad de ejemplos que se pueden citar. A nivel internacional, y con una previsión de lanzamientos hasta 2020 se encuentran las películas y series de Marvel Cinematic Universe ${ }^{1}$ con su saga de películas Los vengadores a la cabeza. A un nivel presupuestario mucho más moderado y a nivel nacional, se encuentran proyectos como El Ministerio del Tiempo, cuya productora ha confirmado tendrá una segunda temporada para 2016 y, la cual además, ya está en proceso de rodaje.

El éxito de estos trabajos, como se verá a lo largo de esta publicación, radica en el proceso más importante de la creación de un proyecto transmedia y se encuentra en la propia definición realizada por Jenkins: crear una experiencia. Crear una experiencia para el prosumidor, este nuevo tipo de público que opina, difunde y/o produce.

\section{Material y método}

El presente trabajo supone una aproximación al concepto de experiencia transmedia desde aspectos estructurales. Es decir, un estudio de los elementos necesarios para su construcción, independientemente del tipo de ficción argumental.

Dado que la creación de la experiencia se dirige al prosumidor, se procede al análisis de éste en términos generales y en proyectos audiovisuales transmedia. $\mathrm{El}$ objetivo de estas observaciones es establecer qué factores se deben tener en cuenta para satisfacerle y cuál es su repercusión en la viabilidad del proyecto.

Para identificar de una manera más concreta las necesidades del prosumidor y sus repercusiones en un proyecto audiovisual transmedia es necesario definir la 
figura de esta nueva concepción del espectador. Esto se realiza a través del análisis de la documentación bibliográfica existente en la actualidad y observar sus acciones en proyectos transmedia. Para ello, se han tenido en consideración el estudio de caso de dos producciones de características,a primera vista, antagónicas: la producción sueca Kung Fury y el proyecto nacional El Ministerio del Tiempo, ambos con fechas de estreno en 2015. Se toma como referencia para este trabajo ambas obras por dos razones precisas: su sistema de producción y el tipo de prosumidor objetivo.

El Ministerio del Tiempo es fruto de las productoras 0nza Partners y Cliffhanger para TVE, una cadena pública estatal de carácter generalista enfocada, mayormente, al público familiar. Kung Fury es el resultado del trabajo del director David Sandberg y su productora Laser Unicorns con la colaboración de Lampray, otra productora audiovisual especializada en postproducción. Su director, guionista y también protagonista dejó su trabajo de dirección publicitaria para llevar a cabo este cortometraje a través de una campaña de crowdfunding. Su tipo de público potencial es muy concreto: aficionados a la comedia y consumidores de productos audiovisuales anteriores relacionados con los blockbusters norteamericanos de los años 80 .

El análisis de ambas creaciones se llevará a cabo teniendo en cuenta los siguientes aspectos:

- Sistema y proceso de producción, distribución y difusión.

- Uso de las redes sociales por parte de la productora.

- Tipos de prosumidores implicados en el proyecto y uso de redes sociales por su parte.

- Repercusión de las acciones de los prosumidores en el proyecto.

De esta manera, se intenta, además de identificar el poder del prosumidor en la producción audiovisual transmedia, observar qué aspectos relacionados dentro 
de la comunicación deben reforzarse y/o mejorar de cara al futuro. Todo ello para obtener un feedback constructivo entre los medios de comunicación y el prosumidor.

\subsection{El prosumidor. De sus múltiples clasificaciones al contenido que genera}

Como ya se ha citado, el origen del término prosumidor surge desde una concepción económica en torno a la década de los años 80 de la mano de Alvin Toffler. Sus predicciones acerca de una tercera etapa en el proceso productivo en la cual el consumidor interviene de manera activa se están produciendo en muchas áreas de consumo, entre ellos, la comunicación.

El prosumidor, en términos comunicativos, ya es una designación del consumidor que incluso está relegando y dejando en obsolescencia a éste. En términos generales, el prosumidor es aquel consumidor que, a su vez, produce contenido. Obviamente, esta definición es una generalización. Por ello, a medida que su participación en los contenidos que ofrecen los medios de comunicación ha ido aumentando, expertos e investigadores han llevado a cabo clasificaciones acerca de los niveles de intervención de este prosumidor.

De los múltiples trabajos y análisis consultados, se hace referencia a tres catalogaciones. A pesar de que sus autores las han realizado desde enfoques diferentes de la relación entre prosumidor- contenido ofertado, se podrá observar que coinciden en unos rasgos comunes.

Hernández y Grandío (2011) consideran que el espectador puede asumir tres tipos de funciones en relación con su implicación con el contenido:

- Difusión: a través de Internet principalmente.

- Interpretación: se generan comunidades de fans en redes sociales o foros para debatir sobre el contenido y analizarlo. 
- Creación: de nuevos relatos ya sean escritos, audiovisuales,interactivos, etc...

Gary Hayes, experto en Redes Sociales y multimedia, establece cinco perfiles de participación en relación a una comunidad web 2.0:

- Consumidor: hace una lectura pasiva de los contenidos.

- Distribuidor: envía información que cree interesante a sus conocidos.

- Crítico: realiza comentarios públicos.

- Editor: mezcla y edita a partir de elementos creados por otros.

- Creador: plantea contenido original.

En su estudio realizado sobre webs televisivas y sus usuarios, Guerrero (2014) establece cuatro modelos de participación.

- Modelo observativo: no deja una marca verbal de su presencia. Se identifica, por ejemplo, a través del número de visitas o los rangos de popularidad de una página concreta.

- Modelo discursivo/argumentativo: comunica sus opiniones acerca del contenido ofrecido.

- Modelo creativo/ divulgativo: crea contenido nuevo ya sea de naturaleza artística o de naturaleza didáctica (ayudar a la compresión de ciertos aspectos del contenido o facilitar su acceso a él).

- Modelo lúdico - jugador: un modelo de participación que Guerrero hace mención para las webs que presentan aplicaciones recreativas. 


\section{MONOGRÁFICO}

Perfil, función, modelo de participación... las clasificaciones aportadas generan denominaciones diferentes pero se puede observar que se refieren a comportamientos del prosumidor comunes. Se pueden encontrar tres acciones principales: Consumir - Difundir - Crear.

Esta última acción citada ha producido el desarrollo del término CGU. Según Fernández Castrillo (2014) el Contenido Generado por el Usuario "engloba todos aquellos formatos de contenido, disponibles a través de redes sociales y plataformas online, creados y distribuidos por uno o varios individuos no profesionales. El resultado final puede ser tanto la invención de una nueva obra como la adaptación de propuestas anteriores, siempre de forma libre y voluntaria. Este tipo de producciones se caracterizan por su alto componente creativo, por lo general son de carácter transmedia y fruto de dinámicas colaborativas en la web".

Como la propia definición establece, el CGU abarca diferentes formatos de contenido. En relación a las producciones audiovisuales transmedia se hace mención especial a la catalogación realizada por Scolari (2013) de los formatos textuales que los prosumidores realizan a través de las redes sociales y otros canales. 0cho son los contenidos más relevantes:

- Sincronizaciones: selección de momentos claves del contenido para su posterior edición en formato multipantalla.

- Recapitulaciones: sumario de los episodios o temporadas precedentes.

- Parodias: remix con otras producciones para crear nuevas interpretaciones paródicas.

- Finales alternativos: producción de finales alternativos después de la emisión final oficial ya sea en tono paródico o manteniendo la continuidad del contenido original.

- Falsos avances: vídeos remixados que anuncian un contenido audiovisual inexistente o cambia el sentido del producto conocido. 
- Falsos openings: comienzo, por ejemplo, de un episodio como si fuera un producto de los años 60 o 70.

- Mashup: vinculación de dos o más mundos narrativos, ya sea con la combinación de imágenes y bandas sonoras o mezclando fragmentos de escenas.

- Adaptaciones: contar una escena pero utilizando otra estética o lenguaje.

Como se puede observar, la mayor parte de la clasificación hace referencia a contenidos audiovisuales pero han de añadirse también materiales gráficos como dibujos, pósters, manipulaciones fotográficas, etc... que además de ser contenido original pueden ser adaptaciones, mashup o finales alternativos. Otro tipo de producción de contenido que también debe tenerse en cuenta y no se incluye dentro la producción audiovisual o gráfica son los cosplay ${ }^{2}$. Este tipo de acciones por parte de los prosumidores de un contenido han producido una serie de comunidades y eventos entorno a los productos de entretenimiento a los que hacen referencia; siendo también estos eventos, puntos de reunión para charlas, debates y otras actividades relacionadas.

Siguiendo las clasificaciones aportadas y los diferentes tipos de contenido que se puede generar, para el presente trabajo se contribuye con una clasificación del prosumidor que será la utilizada en los estudios de caso:

- Consumidor: se limita a un comportamiento pasivo hacia el contenido. Consumo a través del medio ofrecido para ello.

- Distribuidor: difunde el contenido consumido. Ya sea compartiéndolo en sus redes sociales o realizando comentarios o críticas.

- Productor: atendiendo a los tipos de contenido vistos y al contenido original que se puede generar, el productor se subdivide en:

- Productor de Contenido Original, a partir de ahora PCO. Un contenido original puede ser, por ejemplo, la realización de una trama citada en un contenido pero no desarrollada en él. 


\section{MONOGRÁFICO}

- Productor de Contenido Subyacente (PCS). Realiza adaptaciones o versiones del contenido existente y engloba todo tipo de fanart, fanfilm, etc...

\subsection{Alfabetización mediática del prosumidor y el profesional de los medios de comunicación}

En torno a la década de los años 70, debido al auge de los medios de comunicación de masas, surgió la corriente de estudio conocida como Ecología de los Medios fundada por investigadores como Marshal McLuhan y Neil Postamn entre otros. En 1968, Postman definió este marco teórico como el estudio de los medios como ambientes. Más tarde, amplió esta concepción considerando que el uso de la palabra "ecología" se refiere al interés no sólo en los medios, sino también a cómo la cultura se moldea por la interacción entre los humanos y los medios (Postman, 2000).

De esta manera, considerando esta interacción, el prosumidor ha de ser observado, no como un ente global y homogéneo dentro de un marco teórico como en ocasiones sucede, sino como individuos únicos con una edad y un entorno de influencia recíproco. $Y$, los cuales, deberían mantener una relación con los medios basada en un pensamiento crítico y formado.

Surgen así, actividades para la alfabetización mediática ${ }^{3}$ de este nuevo consumidor de medios y del profesional de los medios de comunicación que debe dirigirse a él.

La Unesco ha publicado una serie de documentos dirigidos tanto a alumnos y sus padres como a profesores en educación primaria y secundaria acerca de las competencias mediáticas. Destaca, por ejemplo, Media education. A kit for teachers, students, parents and professionals (2006) que ofrece una serie de conceptos, herramientas para su enseñanza o aplicación y actividades a llevar a cabo para el desarrollo de la formación mediática.

Como se puede apreciar en el título, hay un apartado concreto para los profesionales. La Unesco observa que no sólo padres, profesores y alumnos deben ser 
asesorados en esta materia. Los profesionales deben saber afrontar este nuevas competencias en sus usuarios para saber interactuar con ellos, comprender las variaciones en los límites de la propiedad intelectual o proteger la confidencialidad de los datos aportados. Además de este material, cabe citar la Guía para radios y televisiones sobre la promoción del contenido generado por el usuario y la alfabetización mediática e informacional (2011) en el que se tratan los diferentes tipos de CGU, las oportunidades que ofrecen a los medios de comunicación, el papel de los medios en la alfabetización mediática, etc...

Este tipo de documentos son necesarios analizando estudios como Educación en alfabetización mediática para una nueva ciudadanía prosumidora de GarcíaRuiz, Ramírez-García y Rodríguez-Rosell (2014). En este trabajo se presentaron los resultados de un proyecto de investigación de ámbito estatal con el objetivo de identificar los niveles de competencia mediática de niños y adolescentes. La investigación se realiza a través de una encuesta a una muestra de 2.143 estudiantes de Educación Infantil, Primaria, Secundaria y Bachillerato. Sus autoras concluyeron el trabajo afirmando que dichos estudiantes no poseían las habilidades necesarias para ejercer como "prosumidores mediáticos» y destacaron "la necesidad de complementar la competencia digital establecida en el currículum escolar con la competencia mediática, como elemento clave para desarrollar una "cultura prosumidora»".

En cuanto a la formación de profesionales de los medios de comunicación puede señalarse el estudio de caso presentado por Andreu-Sánchez (2014) realizado con los alumnos de Grado de Publicidad y Relaciones Públicas de la Universitat de Girona en la asignatura "Tendencias del audiovisual contemporáneo". Los alumnos tuvieron que crear proyectos audiovisuales transmedia dirigidos a una audiencia de prosumidores que modificaban el contenido. En sus conclusiones, la autora considera: "El hecho de haber tenido que conseguir que los consumidores de sus webseries se convirtieran también en prosumidores de sus narrativas provocó que los alumnos supieran entender la delgada línea que separa hoy en día al productor del consumidor... La reproducción de esta experiencia docente debe resultar útil para modificar el punto de vista del creador de contenidos audiovisuales que ahora debe tener en cuenta y planificar, por un lado, qué acciones provocará el consumo de su obra en el espectador $y$, por otro, en qué plataforma se producirá dicho consumo". 


\section{MONOGRÁFICO}

Se puede destacar, examinando las consideraciones de ambos estudios y la promoción de la educación mediática realizada por la Unesco, la necesidad de la formación tanto de los prosumidores como de los profesionales responsables de generar contenido para éstos.

\subsection{Kung Fury y El Ministerio del Tiempo. El papel del prosumidor en su éxito}

Tras analizar el prosumidor y los diferentes tipos de acciones que puede llevar a cabo de manera teórica, es necesario analizar su comportamiento en casos prácticos. Se establecen como estudios de caso dos producciones audiovisuales transmedia de diferente proceso de producción y prosumidor objetivo. Como se ha detallado en la metodología, el análisis de estas obras se realiza desde diferentes áreas para poder así establecer los puntos comunes y diferencias entre ambos respecto a su relación con el prosumidor y cómo éste ha repercutido en el proyecto.

Kung Fury es un cortometraje de comedia de 31 minutos de duración cuyo argumento se basa en el viaje en el tiempo que realiza Kung Fury, detective del Departamento de policía de Miami y maestro en artes marciales, desde los ochenta hasta la Segunda Guerra Mundial. Su objetivo es matar a Adofl Hitler, a.k.a. Kung Führer pero un error en la máquina del tiempo le envía hasta la época de los vikingos.

La producción se llevó a cabo gracias a una campaña de crowdfunding en la plataforma Kickstarter desde diciembre de 2013 a enero de 2014, alcanzado la cifra de 630.019 dólares, el triple del objetivo inicial: 200.000. Laser Unicorns (productora del director David Sandberg, también guionista y protagonista del film) y Lampray, ambas de de nacionalidad sueca, fueron las empresas encargadas de gestionar el proyecto.

La película hizo su debut en el Festival de Cannes de 2015 y fue lanzada en YouTube, la plataforma de juego Steam PC, la cadena sueca SVT2 en Suecia, y la cadena estadounidense El Rey Network, el 28 de mayo de 2015. El 1 de junio, la película ya había recibido cerca de diez millones de reproducciones en YouTube 4 . 
El proyecto, desde su fase de recaudación de fondos y diario de producción, se difundió de manera completamente online a través de redes sociales, blogs sobre cine y Youtube, donde se puede visionar el trailer que realizaron para la campaña de crowdfunding. Incluso los prosumidores hicieron promoción del proyecto para conseguir financiación a través de sus cuentas de Facebook o comunidades ${ }^{5}$.

La productora Laser Unicorns lanzó una página web propia para el proyecto (kungfury.com) donde se puede ver el trailer y el corto. Además se pueden econtrar extras como el diario de producción, el videoclip de la canción True Survivor protagonizado por David Hasselhoff y una tienda de merchandising con camisetas y posters. También se tiene acceso a los breakdowns de VFX del cortometraje y al videojuego anexo titulado Kung Fury: Street Rage. Respecto a la relación que se establece con el prosumidor a través de la web, se puede contemplar la recepción de comentarios en la zona de diario de producción y el posteo de las imágenes producidas para el concurso realizado sobre el cortometraje extra Hackerman's hacking tutorials. How to hack time protagonizado por Hackerman, personaje responsable de enviar a Kung Fury al pasado ${ }^{7}$. En cuanto a redes sociales, el proyecto en sí no cuenta con su propia página oficial de Facebook, Twitter o Instagram sino que todo está centralizado por Laser Unicorns que controla las publicaciones o twits que los usuarios realizan y les realiza feedback. En datos estadísticos, en el momento de su consulta (septiembre de 2015) su página de Facebook contaba con más de cien mil personas, tenía casi 9 mil seguidores en Twitter y 21 mil en Instagram. Todo el material que es subido a las redes sociales por parte de la productora es acerca del cortometraje, su director y protagonista, los festivales a los que ha ido el proyecto y a la muestra de los contenidos generados por los fans. Laser Unicorns también cuenta con su canal oficial en Youtube donde se alojan el cortometraje, el trailer, el videoclip, el making off, el cortometraje extra sobre Hackerman, los soundtracks y vídeos relacionados sobre sus visitas a festivales como el Comic-Con International: San Diego.

Los prosumidores que se han acercado al proyecto han sido de los tres tipos que se han calificado con anterioridad (consumidor, distribuidor y productor, ya sea de contenido original o subyacente). El cortometraje cuenta con más de veinte millones de visitas (a fecha septiembre de 2015) y está subtitulado en más de 12 idio- 


\section{MONOGRÁFICO}

mas, además, de una versión doblada en español realizada de manera gratuita y sin ánimo de lucro. En Youtube también puede encontrarse compilaciones anónimas de las reacciones de espectadores ante el visionado del cortometraje. En cuanto a contenido subyacente se encuentran fanarts, cosplays y otros materiales gráficos que se pueden encontrar en diferentes redes sociales.

El Ministerio del Tiempo es una serie emitida en La 1 de TVE. La primera temporada ha contado con ocho capítulos de setenta minutos aproximadamente. La historia parte de una institución gubernamental secreta, El Ministerio del Tiempo, que depende de la Presidencia del Gobierno español.Su objetivo: detectar e impedir que cualquier intruso del pasado llegue a nuestro presente - o viceversa- con el fin de cambiar la Historia para su beneficio. El paso hacia otras épocas se realiza a través de puertas vigiladas por las patrullas del ministerio. Para ello, las patrullas tendrán que viajar al pasado y evitar que lo logren.

Las últimas personas reclutadas por el ministerio son Alonso de Entreríos, soldado del siglo XVI; Amelia Folch, una de las primeras universitarias de España a finales del siglo XIX y Julián Martínez, enfermero del SAMUR del 2015. Alonso, Amelia y Julián se convierten así en el trío protagonista responsable de mantener el orden temporal.

El Ministerio del Tiempo es una producción de 0nza Partners en la parte económica y Cliffhanger, la productora de formatos de Javier y Pablo Olivares, éste último fallecido recientemente. Ambos hermanos fueron los autores originales de la idea y formaron parte del equipo de guionistas de los capítulos. En cuanto a su presupuesto, tanto una de sus productoras ejecutivas, Alicia Yubero, como Javier Olivares, han confirmado haber contado con un presupuesto de 550 mil euros para cada capítulo ${ }^{8}$.

La serie fue estrenada el 24 de febrero de 2015 en La 1 y se pudo seguir tanto por radiodifusión como por la página web de RTVE9 . Los capítulos completos de toda la temporada están disponibles también en la página tras su emisión.

Para su promoción y difusión, el ente público realizó un preestreno para la crítica que le reportó numerosas reseñas positivas tanto en medios de comunicación 
escrita, radio y medios online. También contó con promos internas dentro de sus propios canales, en redes sociales y entrevistas a sus creadores y actores principales. Todo ello creó una ambiente previo de interés como recogió la cadena SER un mes antes de su estreno: "TVE se está volcando en la promoción de su nueva serie 'El Ministerio del Tiempo'. Con un presupuesto que ronda los 600.000 euros por episodio, las primeras imágenes de la nueva ficción de Televisión Española están creando grandes expectativas en torno a ella. No en vano, será el gran estreno de la cadena pública en este 2015 junto con 'Carlos, Rey Emperador “10.

La página web de la serie se encuentra alojada dentro de los contenidos de RTVE y a través de ella se puede acceder al visionado de los capítulos, a material extra como La Puerta del Tiempo (programa en el que se entrevistan a los actores y se explican contenidos de la serie), Curso básico de formación para funcionarios y patrulleros novatos (clips de vídeo con normas sobre el trabajo en el ministerio) y al foro.

El acceso a dicho foro es gratuito y puede entrar a los comentarios de los usuarios para leer y ver los contenidos que suben. En caso de querer responder a alguno de estos usuario o posts, ya es necesario registrarse e identificarse. El foro se subdivide en diversos temas, entre ellos, se encuentra debates sobre los capítulos, los personajes o una sección llamada Conserjería del Ministerio donde se encuentra información general, quejas y dudas técnicas. Entre todos los apéndices en los que se divide el foro, es interesante destacar la Biblioteca del Ministerio en la que los usuarios realizan recomendaciones bibliográficas sobre el período histórico que trata cada capítulo. De cara al productor de contenido se puede encontrar una sección en la que éste puede añadir sus creaciones y ser comentadas por los demás usuarios.

Respecto a las redes sociales, la serie cuenta con perfil en Facebook, Twitter e Instagram. En el momento de la consulta (septiembre de 2015) los seguidores en Facebook eran más de treinta y cuatro mil, contaba con más de treinta y cinco mil seguidores en Twitter y casi tres mil seguidores en su cuenta de Instagram a la que, por cierto, es necesario pedir permiso de acceso de manera previa para poder visualizar el contenido. 


\section{MONOGRÁFICO}

Respecto a las interacciones en el foro, por ejemplo, en La Cafetería del Ministerio (donde se puede discutir, comentar y debatir cualquier tema que no esté recogido en otros apartados del foro) hay 715 mensajes sobre diferentes temas, entre los cuales, se puede encontrar producción de contenido original y contenido subyacente.

En lo referente a Youtube, El Ministerio del Tiempo no tiene ninguna cuenta oficial pero se puede encontrar todo tipo de vídeos respecto a la serie: reviews, trailers, críticas de bloggers, parodias y documentación audiovisual relacionada como entrevistas a los creadores y actores en medios externos a RTVE.

Siguiendo la línea comparativa con Kung Fury, en lo que se refiere a los prosumidores, se encuentran los tres tipos catalogados. En cuanto a los consumidores, según los estándares de medición de cuota de pantalla televisiva, por ejemplo, el primer capítulo contó con un share del 14,8\%, 2.981.000 espectadores ${ }^{11}$. Estas cifras a nivel general de medición de audiencias, es relativamente baja y llevó a la cadena plantearse la renovación de la serie para una segunda temporada. Pero el peso de los seguidores en las redes sociales (durante los primeros capítulos iniciaron una campaña online para que continuara con una segunda temporada), el visto bueno de la crítica y la actividad creativa que ha provocado en los seguidores (autodenominados "ministéricos") provocó la confirmación por parte de RTVE de la segunda temporada. Los materiales generados por los prosumidores son de todo tipo: fanart, parodias, comics, fandoms, cosplays y muchas más. Inclusos algunos seguidores han realizado subtítulos en inglés para el público anglosajón que pueda estar interesado en la serie.

Respecto a la intertextualidad que suelen presentar los proyectos transmedia, ambas producciones presentan elementos temáticos, personajes o referencias a otras producciones. Además de los aspectos referentes a la historia de España, sirva como cita, en el caso de El Ministerio del Tiempo, la alusión que Rodolfo Sancho (actor que interpreta a Julián) realiza sobre su padre y uno de los personajes más famosos que éste interpretó al hacerse llamar Curro Jiménez en uno de sus viajes temporales. 0 también cuando Alonso de Entreríos muestra su estupefacción antes las constantes comparativas con el Capitán Alatriste, personaje creado por Arturo 
Pérez-Reverte a finales de los 90. En lo que concierne a Kung Fury, todo el corto en sí es una referencia a los elementos de cultura de masas de los años 80: la lucha contra una máquina recreativa de videojuegos, la cinta roja que usa el protagonista es la misma que la de Rambo o el personaje del videojuego Street Fighter, Ryu. Incluso, hace un homenaje a los dibujos animados He-man durante una parte del cortometraje.

Como se puede ver ambos proyectos recurren a elementos que provocan una evocación al pasado para producir una vinculación emocional con el prosumidor y, así, éste entre a participar de una manera más activa con el contenido.

\section{Resultados}

Tras realizar el análisis de ambas producciones desde los diferentes puntos de vista citados en la metodología, se puede establecer una tabla comparativa para poder ver de manera global los aspectos comunes y contrarios en lo referente a su tratamiento de la producción y el prosumidor.

\begin{tabular}{|c|c|c|}
\hline & Kung Fury & El Ministerio del tiempo \\
\hline Producción & Crowdfunding & Financiación privada y comercial \\
\hline Distribución & $\begin{array}{ll}\text { - } & \text { Festival de Cannes } \\
\text { - } & \text { Youtube } \\
\text { - } & \text { Tv sueca STV2 } \\
\text { - } & \text { El rey Network (TV EEUU) } \\
\text { - Plataforma de juego Steam } & \text { PC } \\
\end{array}$ & $\begin{array}{l}\text { La } 1 \text { de RTVE } \\
\text { Página web de RTVE }\end{array}$ \\
\hline Difusión & Online & $\begin{array}{ll}- & \text { Online } \\
- & \text { Medios de Comunicación } \\
- & \text { convencionales (Tv, } \\
& \text { radio,prensa) } \\
\end{array}$ \\
\hline
\end{tabular}




\section{MONOGRÁFICO}

\begin{tabular}{|c|c|c|}
\hline & Kung Fury & El Ministerio del tiempo \\
\hline $\begin{array}{l}\text { Uso web y redes } \\
\text { sociales }\end{array}$ & $\begin{array}{c}\text { Web } \\
\text { Interacción mayoritariamente } \\
\text { unidireccional. De la productora } \\
\text { al prosumidor. Poca cantidad de } \\
\text { material generado por el prosu- } \\
\text { midor. } \\
\text { Redes Sociales } \\
\text { Facebook, Twitter, Instagram y } \\
\text { Youtube. Interacción bidireccional } \\
\text { pero controlada por el community } \\
\text { manager. }\end{array}$ & $\begin{array}{c}\text { Web } \\
\text { Interacción bidireccional. Gran } \\
\text { cantidad de contenido e información } \\
\text { aportada por el prosumidor. Gestión } \\
\text { de este contenido por los adminis- } \\
\text { tradores web. } \\
\text { Redes Sociales } \\
\text { Facebook, Twitter, Instagram } \\
\text { (requiere permiso de acceso) } \\
\text { Interacción bidireccional pero } \\
\text { controlada por el community } \\
\text { manager. } \\
\text { Sin cuenta oficial en Youtube }\end{array}$ \\
\hline $\begin{array}{l}\text { Materiales adicional al } \\
\text { principal }\end{array}$ & 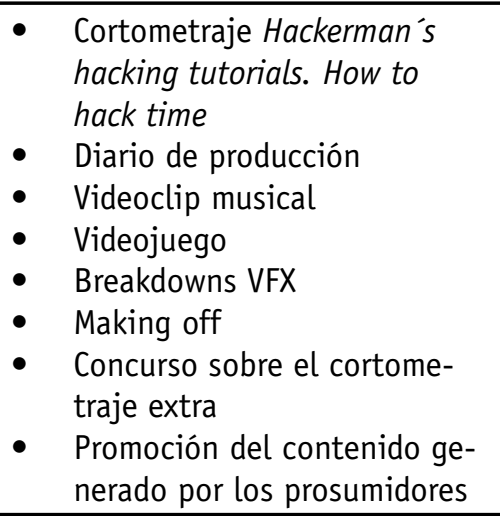 & $\begin{array}{ll}\text { - } & \text { Foro de comunicación } \\
\text { - } & \text { Programa La Puerta del Tiempo } \\
& \text { Programa Curso Básico de } \\
\text { - } & \text { patrulleros nara funcionarios y } \\
\text { - } & \text { Promoción del contenido gene- } \\
& \text { rado por los prosumidores } \\
\text { - } & \text { Making off }\end{array}$ \\
\hline $\begin{array}{l}\text { Tipos de prosumidores } \\
\text { participantes }\end{array}$ & $\begin{array}{l}\text { - } \quad \text { Consumidor } \\
\text { - Distribuidor } \\
\text { - PCO y PCS }\end{array}$ & $\begin{array}{ll}\text { - } & \text { Consumidor } \\
\text { - } & \text { Distribuidor } \\
\text { - } & \text { PCO y PCS }\end{array}$ \\
\hline Intertextualidad & $\begin{array}{l}\text { Evocación al pasado histórico y } \\
\text { social } \\
\text { (referencias a sucesos productores } \\
\text { culturales) }\end{array}$ & $\begin{array}{l}\text { Evocación al pasado social a través } \\
\text { de productos culturales }\end{array}$ \\
\hline $\begin{array}{c}\text { Repercusión del prosu- } \\
\text { midor } \\
\text { en el proyecto }\end{array}$ & $\begin{array}{l}\text { - } \\
\text { - } \\
\text { Efecto llamada para su } \\
\text { visionado por parte de otros } \\
\text { prosumidores }\end{array}$ & $\begin{array}{l}\text { Confirmación de la realización } \\
\text { de la segunda temporada } \\
\text { Efecto llamada para su visiona- } \\
\text { do por parte de otros prosumi- } \\
\text { dores }\end{array}$ \\
\hline
\end{tabular}

Tabla 1: Tabla comparativa sobre el tratamiento de la producción y el prosumidor realizado por Kung Fury y El Ministerio del Tiempo. Fuente: Elaboración propia 
Tras un un trabajo comparativo, puede apreciarse que tanto Kung Fury como El Ministerio del Tiempo presentan:

- Una web para el visionado del contenido y muestra del material anexo.

- Producción de obras que amplifican el universo narrativo.

- Redes sociales para la difusión y comunicación con el prosumidor.

- Intertextualidad.

- Conexión con los tres tipos de prosumidor. Incluyendo en el prosumidor- productor los dos subtipos explicados: de contenido original y de contenido subyacente.

- El prosumidor repercutió en la viabilidad del proyecto.

En cuanto a diferencias en el tratamiento de la producción, su difusión e interacción con el prosumidor, poco elementos pueden encontrarse:

- El inicio de la producción. El director sueco David Sandberg se enfrentaba a su primer cortometraje como director y guionista, además de actor de la cinta, sin ninguna fuente de financiación. Por ello, tuvo que recurrir al sistema de crowdfunding para que personas, a través del trailer que realizó, se interesaran en ayudarle a realizar su obra. Pablo y Javier Olivares, autores de la idea original, tenían un bagaje en producción de proyectos audiovisuales y una relación con TVE anterior como son la serie Isabel o Víctor Ros que permitió una apuesta por el proyecto.

- El Ministerio del Tiempo no cuenta con un canal oficial de Youtube. Esto puede ser comprensible debido a que los servicios de streaming que ofrece pueden encontrarse en la página web de RTVE.

- Kung Fury no tiene una cota de interacción con el público tan alto como El Ministerio del Tiempo. Su nivel de fanart y otros contenidos producidos 


\section{MONOGRÁFICO}

por los prosumidores no son tan difundidos como la serie española, a pesar de encontrarse por la red infinidad de ejemplos de esos contenidos. Las razones para este hecho pueden ser muy diversas. Desde falta de infraestructura para gestionar todo ese contenido como ser una decisión del creador no querer dar promoción a esos contenidos.

\section{Discusión}

Un producto audiovisual transmedia se fundamenta en tres pilares: un universo narrativo, un número de plataformas de expansión de ese universo y un prosumidor que interactúe con el contenido.

Estos elementos y su organización provocan proyectos de una naturaleza expansiva (pueden alargarse en el tiempo y el espacio comunicativo), interactiva (gracias a la relación de comunicación que se establece entre creadores y prosumidores), intertextual (debido a los vínculos que se establecen con otros textos o materiales) y adaptativa (la narración puede transformarse debido a las aportaciones de los prosumidores).

Como se ha podido observar a lo largo de este trabajo, el poder del prosumidor en el desarrollo de una producción audiovisual transmedia es inmenso y vital. Gracias a él fue posible la realización del cortometraje Kung Fury y la renovación de una segunda temporada de El Ministerio del Tiempo. Además, el prosumidor es indispensable para que el proyecto esté vivo y se expanda más allá de los límites que los propios creadores tienen debido a presupuestos y tiempos. Provoca el mantenimiento y crecimiento de la obra gracias a su actividad de promoción altruista, a sus valoraciones y a sus aportaciones. Incluso el consumidor, un tipo de prosumidor pasivo, que solo "consume" el contenido, es importante, por ejemplo, dentro del medio online en el que se pueda mover la obra porque sus visualizaciones posicionan el contenido en los motores de búsqueda de Internet y le dan relevancia.

Sea una producción independiente como el cortometraje sueco o un producto realizado bajo los cánones habituales de la industria cultural, el prosumidor ha hecho posible la existencia de éstos. Y lo ha hecho, asimismo, tanto en una fase de concepción como en una de mantenimiento de la obra. 
La producción audiovisual transmedia requiere del prosumidor y éste necesita sentir que forma parte de ella, que tiene su espacio dentro de la misma. Por ello, como se ha podido ver en ambos estudios de caso, es necesario ofrecerle un sitio para su expresión ya sea en una web, en las redes sociales o en un foro específico. También necesita poder acceder al contenido siempre que quiera y encontrar un feedback a su apoyo al proyecto: a través de concursos, materiales extras, respuestas a sus aportaciones o vías de colaboración en el proyecto de algún otro modo.

Cabe considerar también, el hecho de la existencia previa a ese prosumidor consumidor. Es un prosumidor que apuesta por un contenido no realizado aún (sólo se vislumbra en un trailer, por ejemplo, como el caso de Kung Fury) pero apoya el proyecto difundiendo su campaña de crowdfunding, aportando dinero 0 queriendo ayudar participando como extra de manera gratuita como es el caso del cortometraje sueco. Este prosumidor debe tenerse en cuenta, estudiar los interés que le mueven a querer que un contenido salga adelante y querer participar en él. Debe ser tenido en cuenta, sobre todo, por los productores audiovisuales independientes que, a menudo, se encuentran con la ardua tarea de encontrar financiación para sus proyectos.

Y por último, y debido a todas estas razones expuestas, se concluye esta investigación considerando la importancia de que, tanto la industria cultural como el propio prosumidor, lleven a cabo una educación mediática acerca de su nuevo papel en el mundo audiovisual. De esta manera, su apoyo y su participación en proyectos se realiza de una manera constructiva, crítica y con la suficiente capacidad analítica para tener en cuenta a las obras audiovisuales transmedia que pueden enriquecer el patrimonio cultural y audiovisual.

\section{Notas}

[1] http://marvel.com/movies/all

[2] Representación realista de una idea o de un personaje de ficción a través de disfraces, accesorios o trajes. 
MONOGRÁFICO

[3] La Alfabetización Mediática e Informacional (AMI), según la definición de la Unión Europea (Scott, 2011), "es la capacidad de acceder a los medios de comunicación, comprender y evaluar con criterio diversos aspectos de los mismos y de sus contenidos. Esto también incluye la capacidad de producir contenidos y mensajes mediáticos propios y realizar juicios informados como usuarios de la información y los medios".

[4] https://www.youtube.com/watch?v=bS5P_LAqiVg

[5] Por ejemplo, los administradores de la comunidad de Facebook Renovatio AION 2.7 + Unico Server Hispano lanzaron el 1 de enero de 2014 un mensaje de apoyo para recaudar fondos para la producción. https://www.facebook.com/Renovatio.AION/posts/780675165280306

[6] La mayor parte del cortometraje se ha realizado a través de la utilización de recursos de postproducción como el diseño de la ciudad de Miami, la comisaría, etc... La campaña de crowdfunding se realizó para poder sufragar los gastos de dicha postproducción.

[7] En el cortometraje, Hackerman explica cómo viajar en el pasado pero comete un error y desaparece. En el concurso se anima a los fans a realizar imágenes o montajes visuales sobre dónde creen que se puede encontrar el personaje y se someten a votación del restos de fans de la comunidad.

[8] http://www.panoramaaudiovisual.com/2015/03/02/alicia-yubero-el-ministerio-del-tiempoes-una-serie-muy-cinematografica/ http://beamos.es/2015/03/la-produccion-de-la-serie-el-ministerio-del-tiempo-para-tve/

[9] http://www.rtve.es/television/ministerio-del-tiempo/

[10] http://cadenaser.com/ser/2015/01/27/television/1422369519_461764.htm

[11] http://www.formulatv.com/series/el-ministerio-del-tiempo/audiencias/

\section{Referencias}

Andreu Sánchez, C. (2014) La educación audiovisual y la creación de prosumidores mediáticos. Estudio de caso. En: AdComunica. Revista de estrategias, tendencias e innovación en comunicación. 2014, n ${ }^{0}$ 7, pp. 131- 147 ISSN 2174-0992 Recuperado el 23 de septiembre de 2015, de: http://www.adcomunicarevista. com/ojs/index.php/adcomunica/article/view/149

Fernández Castrillo, C. (2013) Prácticas transmedia en la era del prosumidor: Hacia una definición del Contenido Generado por el Usuario (CGU). En: CIC Cuadernos de Información y Comunicación vol. 19, pp.53-67. (ISSN: 1135-7991). Recuperado el 23 de septiembre de 2015, de: http://revistas.ucm.es/ index.php/CIYC/article/view/43903

Frau-Meigs (Ed.) (2006) Media Education. A Kit for teachers, students, parents and professionals. Unesco. Recuperado el 23 de septiembre de 2015, de: 
http://www.unesco.org/new/es/communication-and-information/resources/ publications-and-communication-materials/publications/full-list/mediaeducation-a-kit-for-teachers-students-parents-and-professionals/

García-Ruiz, R.; Ramírez-García, A.; Rodríguez-Rosell, M.M. (2014) Educación en alfabetización mediática para una nueva ciudadanía prosumidora. En: Comunicar 43 v. XXII, pp. 15-23 (ISSN: 1134-3478; e-ISSN: 1988-3293). Recuperado el 23 de septiembre de 2015, de: http://www.revistacomunicar.com/index.php?con tenido $=$ detalles\&numero $=43 \&$ articulo $=43-2014-01$

Guerrero, M. (2014) Webs televisivas y sus usuarios: un lugar para la narrativa transmedia. Los casos de "Águila Roja" y "Juego de Tronos" en España. En: Comunicación y Sociedad Nueva época, núm. 21, pp. 239-267. (ISSN 0188-252x). Recuperado el 23 de septiembre de 2015, de: http://www. comunicacionysociedad.cucsh.udg.mx/digital/21

Hayes, G. The myth of web 2.0 Non-Participation. Personalize media [blog]. 2007 Recuperado el 23 de septiembre de 2015, de: http://www.personalizemedia. com/?s=editors\&searchsubmit=

Hernández Pérez, M.; Grandío Pérez, M. M. Narrativa crossmedia en el discurso televisivo de Ciencia Ficción. Estudio de Battlestar Galactica (2003-2010). En: Área Abierta No 28. Marzo 2011, pp 1-20. (Referencia: AA28.1103.143) Recuperado el 23 de septiembre de 2015, de: http://revistas.ucm.es/index. $\mathrm{php} / \mathrm{ARAB} /$ article/view/4873

Jenkins, H. Transmedia Storytelling. Moving characters from books to films to video games can make them stronger and more compelling. MIT Technology Review [blog]. 15 de enero de 2003 Recuperado el 23 de septiembre de 2015, de: http://www.technologyreview.com/news/401760/transmedia-storytelling/

Martin, S. (2011) Guía para radios y televsiones sobre la promoción del contenido generado por el usuario y la alfabetización mediática e informacional Recuperado el 23 de septiembre de 2015, de: http://unesdoc.unesco.org/ images/0021/002155/215549s.pdf

Postman, N. (2000) The Humanism of Media Ecology. En: Proceedings of the Media Ecology Association. Volumen 1, p. 10-27 Recuperado el 23 de septiembre de 2015, de: http://www.media-ecology.org/publications/MEA_proceedings/v1/ humanism_of_media_ecology.html

Scolari, C. A (2010) Ecología de los medios. Mapa de un nicho teórico. En: Quaderns 
del CAC [en línea] 34, vol. XIII (1) - junio 2010, pp 17-25.(ISSN: 1138-9761) Recuperado el 23 de septiembre de 2015, de: http://www.cac.cat/pfw_files/ cma/recerca/quaderns_cac/034_Scolari_ES.pdf

Scolari, C. A. (2013) Narrativas transmedia. Cuando todos los medios cuentan. Centro Libros PAPF, S.L.U; Grupo Planeta. Barcelona, ISBN: 978-84-234-1336- 